\title{
Modeling nutrient in-stream processes at the watershed scale using Nutrient Spiralling metrics
}

\author{
R. Marcé ${ }^{1,2}$ and J. Armengol ${ }^{2}$ \\ ${ }^{1}$ Catalan Institute for Water Research (ICRA), Edifici H2O, Parc Científic i Tecnològic de la Universitat de Girona, \\ 17003 Girona, Spain \\ ${ }^{2}$ Fluvial Dynamics and Hydrological Engineering (FLUMEN), Department of Ecology, University of Barcelona, \\ Diagonal 645, 08028 Barcelona, Spain
}

Received: 17 November 2008 - Published in Hydrol. Earth Syst. Sci. Discuss.: 23 January 2009

Revised: 29 June 2009 - Accepted: 29 June 2009 - Published: 6 July 2009

\begin{abstract}
One of the fundamental problems of using largescale biogeochemical models is the uncertainty involved in aggregating the components of fine-scale deterministic models in watershed applications, and in extrapolating the results of field-scale measurements to larger spatial scales. Although spatial or temporal lumping may reduce the problem, information obtained during fine-scale research may not apply to lumped categories. Thus, the use of knowledge gained through fine-scale studies to predict coarse-scale phenomena is not straightforward. In this study, we used the nutrient uptake metrics defined in the Nutrient Spiralling concept to formulate the equations governing total phosphorus instream fate in a deterministic, watershed-scale biogeochemical model. Once the model was calibrated, fitted phosphorus retention metrics where put in context of global patterns of phosphorus retention variability. For this purpose, we calculated power regressions between phosphorus retention metrics, streamflow, and phosphorus concentration in water using published data from 66 streams worldwide, including both pristine and nutrient enriched streams.

Performance of the calibrated model confirmed that the Nutrient Spiralling formulation is a convenient simplification of the biogeochemical transformations involved in total phosphorus in-stream fate. Thus, this approach may be helpful even for customary deterministic applications working at short time steps. The calibrated phosphorus retention metrics were comparable to field estimates from the study watershed, and showed high coherence with global patterns of retention metrics from streams of the world. In this sense, the fitted phosphorus retention metrics were similar to field values measured in other nutrient enriched streams. Analysis of the bibliographical data supports the view that nutrient enriched streams have lower phosphorus retention effi-
\end{abstract}

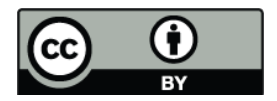

Correspondence to: R. Marcé (rmarce@icra.cat) ciency than pristine streams, and that this efficiency loss is maintained in a wide discharge range. This implies that both small and larger streams may be impacted by human activities in terms of nutrient retention capacity, suggesting that larger rivers located in human populated areas can exert considerable influence on phosphorus exports from watersheds. The role of biological activity in this efficiency loss showed by nutrient enriched streams remained uncertain, because the phosphorus mass transfer coefficient did not show consistent relationships with streamflow and phosphorus concentration in water. The heterogeneity of the compiled data and the possible role of additional inorganic processes on phosphorus in-stream dynamics may explain this. We suggest that more research on phosphorus dynamics at the reach scale is needed, specially in large, human impacted watercourses.

\section{Introduction}

Excess human-induced nutrient loading into rivers has led to freshwater eutrophication (Vollenweider, 1968; Heaney et al., 1992; Reynolds, 1992) and degradation of coastal areas and resources on a global scale (Walsh, 1991; Alexander et al., 2000; McIsaac et al., 2001). Thus, eutrophication assessment and control are important issues facing natural resource managers, especially in watersheds with high human impact. Control measures are frequently based on bulk calculations of river nutrient loading (e.g., Marcé et al., 2004), on crude mass-balance approximations (Howarth et al., 1996; Jaworski et al., 1992), on the nutrient export coefficient methodology (Beaulac and Reckhow, 1982), or on several refinements derived from it (Johnes, 1996; Johnes et al., 1996; Johnes and Heathwaite, 1997; Smith et al., 1997; Alexander et al., 2002). All these methodologies work at the seasonal scale at best, and only include very rough representations of the underlying processes involved in nutrient biogeochemistry and transport.

Published by Copernicus Publications on behalf of the European Geosciences Union. 
By contrast, watershed-scale deterministic models can work at any time-scale, and they describe transport and loss processes in detail with mathematical formulations accounting for the spatial and temporal variations in sources and sinks in watersheds. These advantages, and the increasing computing power available to researchers, have prompted the development of many of such models (e.g. HSPF, Bicknell et al., 2001; SWAT, Srinivasan et al., 1993; INCA, Whitehead et al., 1998; AGNPS, Young et al., 1995; RIVERSTRAHLER, Garnier et al., 1995; MONERIS, Behrendt et al., 2000). On the other hand, the complexity of deterministic models often creates intensive data and calibration requirements, which generally limits their application in large watersheds. Deterministic models also lack robust measures of uncertainty in model coefficients and predictions, although recent developments for hydrological applications can be used in biogeochemical models as well (Raat et al., 2004). Nonetheless, deterministic models are abstractions of reality that can include unrealistic assumptions in their formulation.

A frequently ignored problem when using watershed-scale models is the uncertainty involved in aggregating the components of fine-scale deterministic models in watershed applications (Rastetter et al., 1992), and in extrapolating the results of field-scale measurements to larger spatial scales. This is important because the ability to use the knowledge gained through fine-scale studies (e.g. nutrient uptake rate for different river producers communities, nutrient fate in the food web, and so on) to predict coarse-scale phenomena (e.g. the overall nutrient export from watersheds) is highly desirable. However, incorporating interactions between many components in a big-scale model can be cumbersome, simply because the number of possible interactions may be very large (Beven, 1989). The usual strategy to avoid a model including precise formulations for each interaction (and thus the counting of thousands of parameters) is to lump components into aggregated units. But although lumping might reduce the number of parameters to a few tens, we still cannot guarantee that the information obtained during fine-scale research will apply to lumped categories. The behavior of an aggregate is not necessarily equivalent to the sum of the behaviors of the fine-scale components from which it is constituted (O'Neill and Rust, 1979).

Considering nutrient fate modeling at the watershed scale, the processes involved in in-stream biogeochemical transformations are a major source of uncertainty. The working unit for the nutrient in-stream processes of most watershed-scale models is the reach. Within this topological unit, several formulations for biogeochemical reactions are included depending on the model complexity (e.g. adsorption mechanisms, algae uptake, benthic release, decomposition). However, if the main research target is to describe the nutrient balance of the system and we can ignore the detailed biogeochemical transformations, a much more convenient in-stream model would consist of a reach-lumped formulation of stream nutrient uptake. This will save a lot of adjustable parameters.
Moreover, if this uptake is empirically quantifiable at the reach scale, then we will be able to apply the field research to the model without the problems associated with upscaling results from fine-scale studies. In the case of nutrient fate in streams, the Nutrient Spiralling concept (Newbold et al., 1981) could be a convenient simplification of the nutrient biogeochemical transformations involved, because the nutrient spiralling metrics are empirically evaluated at the reach scale (Stream Solute Workshop, 1990), the same topological unit used by most watershed-scale models. Within this framework, the fate of a molecule in a stream is described as a spiral length, which is the average distance a molecule travels to complete a cycle from the dissolved state in the water column, to a streambed compartment, and eventually back to the water column. The spiral length consists of two parts: the uptake length $\left(S_{w}\right)$, which is the distance traveled in dissolved form, and the turnover length, which is the distance traveled within the benthic compartment. Usually, $S_{w}$ is much longer than turnover length, and research based on the nutrient spiralling concept focuses on it. $S_{w}$ is evaluated at the reach scale, with nutrient enrichment experiments (Payn et al., 2005), following nutrient decay downstream from a point-source (Martí et al., 2004), or with transportbased analysis (Runkel, 2007).

In this study, we explored the possibility of using the mathematical formulation of the Nutrient Spiralling concept to define the in-stream processes affecting total phosphorus concentration in a customary watershed-scale deterministic model, and checked whether the final model calibration was consistent with global patterns of phosphorus retention in river networks. First, we manipulated the model source code to include the nutrient spiralling equations. Then, we implemented the model for a real watershed, and let a calibration algorithm fit the model to observed data. Next, we analyzed whether the final model was a realistic representation of the natural system, comparing the adjusted nutrient spiraling metrics in the model with values from field-based research performed in the watershed under study. Finally, we assessed how the adjusted nutrient spiraling metrics fit in global relationships between phosphorus spiralling metrics, discharge, and nutrient concentration.

\section{Materials and methods}

\subsection{Study site}

We explored the possibility of using the Nutrient Spiralling formulation for the in-stream modules of a watershed-scale model in the Ter River watershed (Spain), including all watercourses upstream from Sau Reservoir (Fig. 1). We considered $1380 \mathrm{~km}^{2}$ of land with a mixture of land use and vegetation. The headwaters are located in the Pyrenees above $2000 \mathrm{~m}$ a.s.l., and run over igneous and metamorphic rocks covered by mountain shrub communities and alpine 


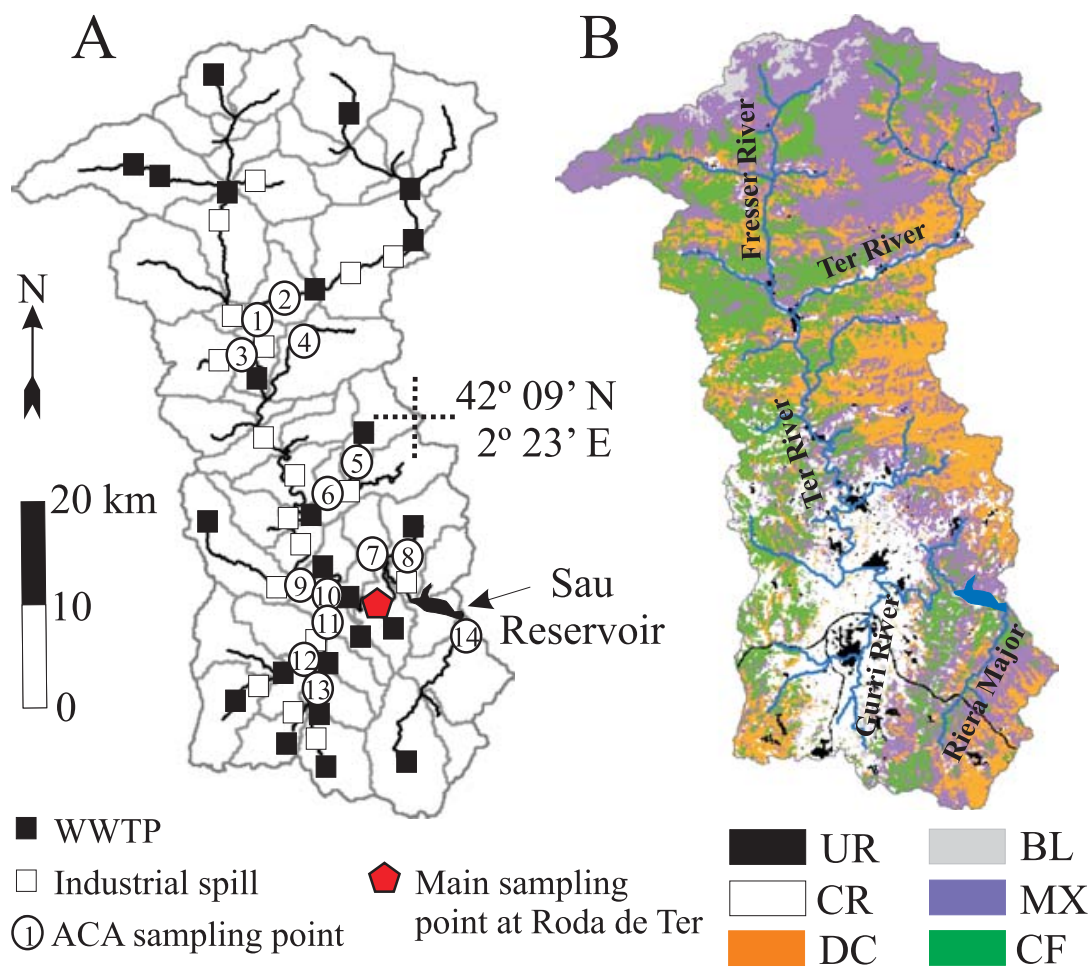

Fig. 1. (a) River total phosphorus (TP) sampling points and TP point sources in the Ter River watershed. Subbasins delineated for HSPF simulation are also shown. (b) Main watercourses and land uses in the watershed (UR: urban; CR: unirrigated crops; DC: deciduous forest; BL: barren land; MX: for clarity, meadows, shrublands, and few portions of oak forest are included here; CF: conifers forest).

meadows. Downstream, the watercourses are surrounded by a mixture of conifer and deciduous forest, and sedimentary rocks become dominant. The Ter River then enters the alluvial agricultural plain $(400 \mathrm{~m}$ a.s.1.) where non-irrigated crops dominate the landscape. The main Ter River tributaries are the Fresser River in the Pyrenees, the Gurri River on the agricultural plain, and Riera Major in the Sau Reservoir basin.

As usual in the Mediterranean region, precipitation is highly variable in both space and time. Most of the watershed has annual precipitation around $800 \mathrm{~mm}$, although in the mountainous north values rise to $1000 \mathrm{~mm}$, and locally up to $1200 \mathrm{~mm}$. Precipitation falls mainly during April-May and September, and falls as snow in the North headwaters during winter. Ter River daily mean water temperature at Roda de Ter (Fig. 1) ranges from 3 to $29^{\circ} \mathrm{C}$, whereas there is a marked variability in the air temperature range across the watershed.

The Ter River watershed includes several urban settlements, especially on the agricultural plain (100000 inhabitants). Industrial activity is important, with numerous phosphorus point-sources (Fig. 1a) coming from textile and meat production. Effluents from wastewater treatment plants (WWTP) are also numerous. Additionally, pig farming is an increasing activity, generating large amounts of slurry that are directly applied to the nearby crops as a fertilizer, at a rate of $200 \mathrm{~kg} \mathrm{Pha}^{-1} \mathrm{yr}^{-1}$ (Consell Comarcal d'Osona, 2003). The median flow of the river at Roda de Ter (Fig. 1) is $10 \mathrm{~m}^{3} \mathrm{~s}^{-1}$, and total phosphorus (TP) concentration frequently exceeds $0.2 \mathrm{mg} \mathrm{PL}^{-1}$. However, streamflow shows strong seasonality, with very low values during summer (less than $1 \mathrm{~m}^{3} \mathrm{~s}^{-1}$ during extreme droughts) and storm peaks during spring and autumn exceeding $200 \mathrm{~m}^{3} \mathrm{~s}^{-1}$.

\subsection{Modeling framework}

The main target of the watershed-scale model was the prediction of daily TP river concentration at Roda de Ter (Fig. 1a). We used the Hydrological Simulation ProgramFortran (HSPF), a deterministic model that simulates water routing in the watershed and water quality constituents (Bicknell et al., 2001). HSPF simulates streamflow using meteorological inputs and information on several terrain features (land use, slope, soil type), and it discriminates between surface and subsurface contributions to streams. HSPF splits the watershed into different sub-basins (e.g., Fig. 1a). Each sub-basin consists of a river reach, the terrain drained by it, and upstream and downstream reach boundaries to solve for lotic transport across the watershed. Only limited, very rough spatial resolution is considered inside sub-basins, and explicit spatial relationships are present only in the form of reach boundaries. HSPF solves the hydrological and 


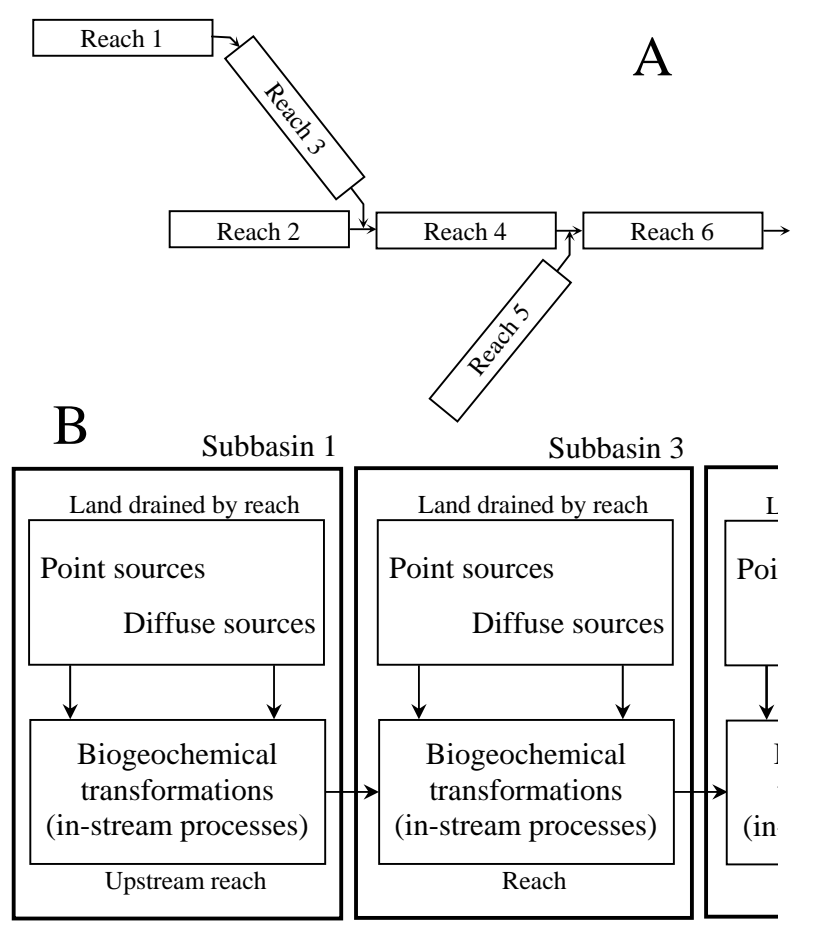

Fig. 2. (a) Schematic representation of hierarchical resolution of subbasins in a HSPF simulation to adequately represent water and constituents routing across a reach network. (b) Diagram showing the main biogeochemical processes solved inside each subbasin in a HSPF simulation.

biogeochemical equations of the model inside sub-basins, and the resolution of each sub-basin is hierarchically sorted in order to adequately simulate mass and energy transport as water moves downstream (Fig. 2).

Hydrology and river temperature have previously been simulated and validated in the Ter River watershed using HSPF on a daily and hourly time scale (Marcé et al., 2008; Marcé and Armengol, 2008). Figure 3 shows the simulated daily river streamflow and temperature against observations at Roda de Ter for sampling dates when river TP concentration was available. For simulations included in this study, we used the water routing and river temperature results from Marcé et al. (2008) and Marcé and Armengol (2008), respectively. We also refer the reader to Marcé et al. (2008) for the sub-basin delineation procedure and other details of the model.

\subsection{Point sources and diffuse inputs of phosphorus}

TP concentration and water load information for point sources comes from the Catalan Water Agency (ACA), and consisted of a georrefenced, heterogeneous database with very detailed data for some spills, and crude annual values for others. Due to the lack of precision in some figures of the database we decided to include in the model an ad-

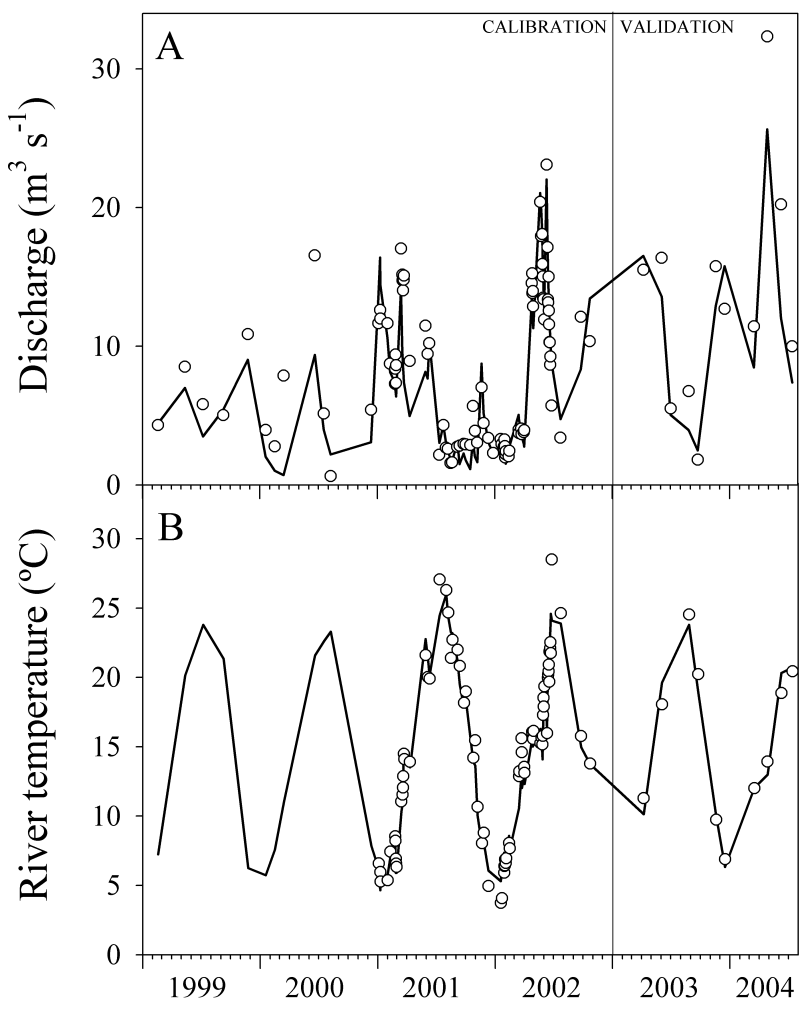

Fig. 3. (a) Observed (open circles) and modeled (line) discharge at Roda de Ter for total phosphorus (TP) sampling dates (from Marcé et al., 2008). (b) Observed (open circles) and modeled (line) mean daily river temperature at Roda de Ter for TP sampling dates (from Marcé and Armengol, 2008).

justable multiplicative factor for WWTP inputs $\left(C_{w}\right)$ and another for industrial spills $\left(C_{i}\right)$, in order to correct for potential monotonous biases in the database (Table 1). Thus, the daily TP load from point sources for a particular reach modeled in HSPF was the sum of all spills located in the corresponding subbasin times the correction factor. Note that the correction factor value was the same for all spills of the same kind (i.e., industrial or WWTP) throughout the watershed.

Diffuse TP inputs into the watercourses were modeled using water routing results from Marcé et al. (2008). Since we were mainly interested in the in-stream processes, and in order to keep the model structure as simple as possible, we calibrated the model against river TP data collected on sampling dates for which there was no surface runoff for at least seven days previously. Thus, we ignored TP transport in surface runoff. TP concentration in interflow and groundwater flow (diffuse sources in Fig. 2) was modeled assuming power dilution dynamics. We modified the HSPF code to include the following formulations

$\mathrm{TP}_{i}=a_{i} \times Q_{i}^{b_{i}}$

$\mathrm{TP}_{g}=a_{g} \times Q_{g}^{b_{g}}$ 
Table 1. Prior ranges and final adjusted values during calibration of parameters used in the definition of the total phosphorus (TP) model. Equation numbers refer to equations in the text.

\begin{tabular}{|c|c|c|c|c|}
\hline \multicolumn{2}{|c|}{ Description } & Units & Upper and lower limits & SCE-UA value \\
\hline \multicolumn{5}{|c|}{ In-stream TP decay } \\
\hline$v_{f}$ & Watershed scale uptake velocity (Eq. 4) & $\mathrm{ms}^{-1}$ & $2.8 \times 10^{-11}-2.5 \times 10^{-5}$ & $1.41 \times 10^{-6}$ \\
\hline TC & Temperature correction factor for $v_{f}$ (Eq. 4 ) & ${ }^{\circ} \mathrm{C}^{-1}$ & $1-2$ & 1.06 \\
\hline \multicolumn{5}{|c|}{ Diffuse TP inputs } \\
\hline$b_{i}$ & Slope for TP vs. interflow discharge (Eq. 1) & $\mathrm{mm}^{-1}$ & $0-1.8$ & 0.56 \\
\hline$a_{i}$ & Intercept for TP vs. interflow discharge (Eq. 1) & $\operatorname{mg~PL} L^{-1}$ & $3.5 \times 10^{-5}-0.38$ & 0.002 \\
\hline$b_{g}$ & Slope for TP vs. groundwater discharge (Eq. 1) & $\mathrm{mm}^{-1}$ & $0-1.8$ & 0.026 \\
\hline$a_{g}$ & Intercept for TP vs. groundwater discharge (Eq. 1) & $\mathrm{mg} \mathrm{PL}^{-1}$ & $3.5 \times 10^{-5}-0.38$ & 0.05 \\
\hline \multicolumn{5}{|c|}{ Point-sources correction } \\
\hline$C_{w}$ & Correction factor for TP load fom WWTP's & - & $0-9$ & 0.63 \\
\hline$C_{i}$ & Correction factor for TP load from industrial spills & - & $0-9$ & 1.16 \\
\hline
\end{tabular}

where $\mathrm{TP}_{i}$ and $\mathrm{TP} g$ are $\mathrm{TP}$ concentration $\left(\mathrm{mg} \mathrm{PL}^{-1}\right)$ in interflow and groundwater discharge, respectively. $Q_{i}$ and $Q_{g}$ are the interflow and groundwater discharge $(\mathrm{mm})$ coming from the land drained by the reach. $a_{i}, a_{g}, b_{i}$, and $b_{g}$ are adjustable parameters of the corresponding power law. Note that we did not consider spatial heterogeneity for these parameters (i.e., a different adjustable value for each sub-basin). Thus, they should be considered as averages for the entire watershed. However, as we will see later, river TP data for calibration of the model came from one sampling point. As a consequence, the optimized parameter values will more closely correspond to the situation around this sampling point, and they will be less reliable far from it.

\subsection{In-stream TP model definition}

HSPF includes a module to simulate the biogeochemical transformations of TP inside river reaches (i.e., the in-stream processes, Fig. 2b). Several processes can be defined in this module, including assimilation/release by algae, adsorption/desorption mechanisms, sedimentation of particulate material, decomposition of organic materials, among others (Bicknell et al., 2001). One of the objectives of this study was to explore the possibility of simplifying all these in-stream processes using an aggregate process: TP retention as defined by the Nutrient Spiralling concept. We modified the HSPF code to include formulations that follow.

The in-stream TP fate was modeled as a first order decay following the Stream Solute Workshop (1990) and can be conceptualized as

$$
\begin{aligned}
\frac{\partial \mathrm{TP}}{\partial t}= & -\frac{Q}{A} \frac{\partial \mathrm{TP}}{\partial \mathrm{x}}+\frac{1}{A} \frac{\partial}{\partial \mathrm{x}}\left[A D \frac{\partial \mathrm{TP}}{\partial \mathrm{x}}\right]+\frac{Q_{i}}{A}\left(\mathrm{TP}_{i}-\mathrm{TP}\right) \\
& +\frac{Q_{g}}{A}(\mathrm{TP} g-\mathrm{TP})-k_{c} \mathrm{TP}
\end{aligned}
$$

where $t$ is time (s), $x$ is distance $(\mathrm{m}), Q$ is river discharge $\left(\mathrm{m}^{3} \mathrm{~s}^{-1}\right), A$ is river cross-sectional area $\left(\mathrm{m}^{2}\right)$, and $k_{c}\left(\mathrm{~s}^{-1}\right)$ is an overall uptake rate coefficient. $Q_{i}$ and $Q_{g}$ are as in Eq. (1) but expressed in $\mathrm{m}^{3} \mathrm{~s}^{-1}$. The first term of the equation refers to advection, the second to dispersion, and third and fourth to lateral subsurface inflows. In the context of the HSPF modeling framework, all these terms refer to TP inputs to the reach, and were solved as explained above. Note that the in-stream model is solved independently inside each reach defined in HSPF, guaranteeing some degree of spatial heterogeneity for the hydraulic behavior. Then, although the formulation assumes steady flow, a particular solution of this assumption only applies inside a modeled reach during one time step of the model (one hour), not to the entire river network.

The last term in Eq. (2) simulates solute transfers between water column and benthic compartment (this is what we considered in-stream processes in this paper). Of course this represents an extremely simplified formulation, and must be interpreted as a net transport, because more complex settings account for independent dynamics of benthic release and concentration in one or more benthic compartments (Newbold et al., 1983). One important limitation of this formulation is that $k_{c}$ is a constant, and applying a single value in a system with varying water depth may be very unrealistic. A much more convenient formulation of the last term in Eq. (2) considers solute transfers as a flux across the sediment/water interface, by means of a mass transfer coefficient $\left(v_{f}, \mathrm{~m} \mathrm{~s}^{-1}\right)$ :

$$
-k_{c} \mathrm{TP}=-\frac{v_{f}}{h} \mathrm{TP}
$$

where $h$ is river depth. Obviously, from this we can establish $v_{f}=h \times k_{c}$, which implies that $v_{f}$ is a scale free parameter (Stream Solute Workshop, 1990). We modified the HSPF code to incorporate this formulation as the only modeled instream process, also including a built-in HSPF temperature correction factor. The final formulation of the in-stream processes was

$$
-k_{c} \mathrm{TP}=-\frac{v_{f} T C^{\left(T_{w}-20\right)}}{h} \mathrm{TP}
$$


where $T C$ is the temperature correction factor and $T_{w}\left({ }^{\circ} \mathrm{C}\right)$ is river water temperature. Thus, the in-stream module of the watershed-scale model only included two adjustable parameters (Table 1).

$v_{f}$ is related to the Nutrient Spiralling metric $S_{w}$ through the following relationship

$S_{w}=\frac{u h}{v_{f}}$

where $u$ is water velocity $\left(\mathrm{m} \mathrm{s}^{-1}\right)$. However, note that this is true only if violation of the steady flow assumption in Eq. (2) is minor. Since nutrient uptake experiments in rivers and streams usually report $S_{w}$ values for representative reaches, we can calibrate the watershed model with observed data and compare the obtained $S_{w}$ with reported values from real systems (including data from the Ter River watershed).

Regarding Eq. (4), we are assuming that areal uptake rate $\left(U=v_{f} \times \mathrm{TP}\right)$ is linearly dependent on nutrient concentration. Although a Monod function relating $U$ and nutrient concentration has been proposed (Mulholland et al., 1990), the linear rule applies even at very high phosphorus concentrations (Mulholland et al., 1990), and there is no conclusive empirical evidence of non-linear kinetics relating $v_{f}$ and phosphorus concentration in rivers (Wollheim et al., 2006), specially in large streams. Still regarding Eq. (4), we are assuming a monotonous effect of temperature on solute transfer in the range of water temperatures measured in our streams.

As above, note that we did not consider spatial heterogeneity for the nutrient retention parameters (i.e., different adjustable values for each reach defined in the HSPF model). Thus, adjusted Nutrient Spiralling metrics reported in this study $\left(v_{f}\right.$ and $S_{w}$ ) should be considered as averages for the entire watershed. As in the preceding section, optimized parameter values will more closely correspond to the situation around the TP sampling point, and they will be less reliable as we move upstream.

\subsection{Calibration strategy}

River TP concentration data for this study came from the Sau Reservoir long-term monitoring program, which includes a sampling point upstream of the reservoir at Roda de Ter (Fig. 1a). Sampling was weekly to monthly, from January 1999 to July 2004. Samples were analyzed using the alkaline persulfate oxidation method (Grasshoff et al., 1983). Among available data, we only considered 106 river TP concentration values measured on sampling dates for which there was no surface runoff for at least seven days previously (see Sect. 2.3). These data were the basic data used for calibration and validation of the HSPF model. In addition, TP data from 14 sampling stations run by the local water agency (Agència Catalana de l'Aigua, ACA) were used as a supplementary set for model verification (Fig. 1a). The amount of data from these stations was highly variable, and the reliability of many figures was dubious (e.g. precision only to one significant digit on most occasions). Thus, we did not consider this information adequate for model calibration.

We calibrated the 8 parameter-model (Table 1) using TP data collected from the Roda de Ter sampling point from 1999 to 2002. TP data for the period 2003-2004 were left for the validation check and not used during calibration. However, since river discharge used during calibration was a modeled variable, we corrected the possible effects of errors in discharge simulation on modeled TP values. TP concentration in the river at Roda de Ter followed a power dilution dynamics with discharge $\left(\mathrm{TP}=0.35 \times\right.$ Discharge $^{-0.36}$, $p<0.0001, n=106, r^{2}=0.45$ ). Therefore, any mismatch between observed and modeled discharge will have a profound effect on the calibration process, especially at low discharges. To solve this problem, we performed calibration on a corrected TP observed series, using

$\mathrm{TP}_{C}=\mathrm{TP} \frac{\mathrm{TP}_{\text {mod }}^{\prime}}{\mathrm{TP}_{\mathrm{obs}}^{\prime}}$

where $\mathrm{TP}_{c}$ is the corrected $\mathrm{TP}$ observed value. $\mathrm{TP}_{\text {mod }}^{\prime}$ and $\mathrm{TP}_{\text {obs }}^{\prime}$ are the TP values predicted by the above power regression using the modeled and the observed discharge, respectively (Fig. 3a). The correcting quotient in Eq. (6) averaged 1.09 for all TP data used during calibration.

Calibration was automatically done using the Shuffled Complex Evolution algorithm (SCE-UA), which was developed to deal with highly non-linear problems (Duan et al., 1992). From an initial population of randomly generated parameters, the algorithm uses shuffling, competitive evolution, and random search to efficiently find the parameter set that minimizes an objective function (OF). In this case, the OF was the sum of the squared errors between model outcomes and corresponding $\mathrm{TP}_{c}$ values. We performed the calibration run using SCE-UA as implemented in the PEST package (Doherty, 2003), with parameter bounds detailed in Table 1.

\subsection{Model structure coherence and global patterns of phosphorus retention metrics}

In order to assess whether the final model structure was realistic, we compared the adjusted values of the nutrient spiraling metrics in the HSPF model with values from field-based research performed in the watershed under study and in other systems worldwide. The comparison with metrics measured in the Ter watershed was difficult, because published field estimations of Nutrient Spiralling metrics from the Ter watershed mostly report data for pristine streams (Martí and Sabater, 1996; Butturini and Sabater, 1998), while the calibration of the HSPF model is based on data collected downstream a highly human impacted area. Thus, comparing retention metrics from these studies with the fitted metrics in our model could be misleading. Fortunately, Martí et al. (2004) reported $v_{f}$ for two phosphorus retention experiments in a reach in the impaired Riera de Tona (Gurri River tributary, Fig. 1b), a location close to our sampling TP point. 
We could take the comparison between modeled retention metrics and field-based estimations a step further. During recent years, researchers have accumulated data that suggest nutrient enriched streams have lower retention efficiency (i.e., lower $v_{f}$ or higher $S_{w}$ ) than pristine streams (Doyle et al., 2003; Martí et al., 2004; Haggard et al., 2005; Merseburger et al., 2005; Gücker and Pusch, 2006; Ruggiero et al., 2006). To test how our model results fit into this picture, we collected $S_{w}$ and $v_{f}$ results for phosphorus from pristine and nutrient enriched streams. If fitted $S_{w}$ and $v_{f}$ in our model are realistic approximations of real values, they must resemble values measured in impaired streams, and should be coherent with observed relationships between retention metrics, streamflow, and phosphorus concentration. Note that collected results come from very heterogeneous field procedures (nutrient additions, nutrient decay downstream from a point source, isotopic tracers), and that they lump seasonal studies with one-measure data, and habitat specific experiments with whole stream determinations. The most important implication is that while retention metrics for pristine streams are usually assessed with nutrient enrichment experiments, thus reporting gross retention (Martí et al., 1997), most data from impaired streams comes from ambient nutrient decay experiments, which must be considered reporting net retention metrics. Obviously, our model estimates for the Ter watershed should be considered as a net retention. Finally, values from the literature are based on dissolved inorganic phosphorus retention while our model predicts TP. Although this could introduce some bias in the analysis, the low proportion of particulate phosphorus in this human impacted stream (36\% in average) suggests that the comparison between our results and the bibliographical values is acceptable.

\section{Results}

During HSPF calibration with SCE-UA, convergence to an optimized parameter set (see Table 1) was achieved after 7000 model runs. Factors for point source correction $\left(C_{i}\right.$ and $C_{w}$ ) were adjusted to values different than one, suggesting that the available database for point sources had significant biases. The TP load from WWTP seemed to be overestimated in the database, while the industrial spills were slightly underestimated. Applying $C_{w}$ and $C_{i}$ for the mean annual TP loads we obtained $19000 \mathrm{~kg} \mathrm{Pyr}^{-1}$ from WWTP and $12300 \mathrm{~kg} \mathrm{Pyr}^{-1}$ from industrial spills. Considering the diffuse TP inputs, the power function fitted for groundwater TP concentration had a very gentle slope $\left(b_{g}\right.$, Table 1), implying that $\mathrm{TP} g$ was nearly a constant value in the range of $Q_{g}$ modeled in the Ter watershed (TP $g$ around $\left.0.06 \mathrm{mg} \mathrm{PL}^{-1}\right)$. By contrast, the slope for the power relationship between $\mathrm{TP}_{i}$ and $Q_{i}$ defined a clear dilution dynamics, with $\mathrm{TP}_{i}$ concentration ranging from 0.6 to $0.04 \mathrm{mg} \mathrm{PL}^{-1}$ depending on $Q_{i}$ values. Using these power relationships

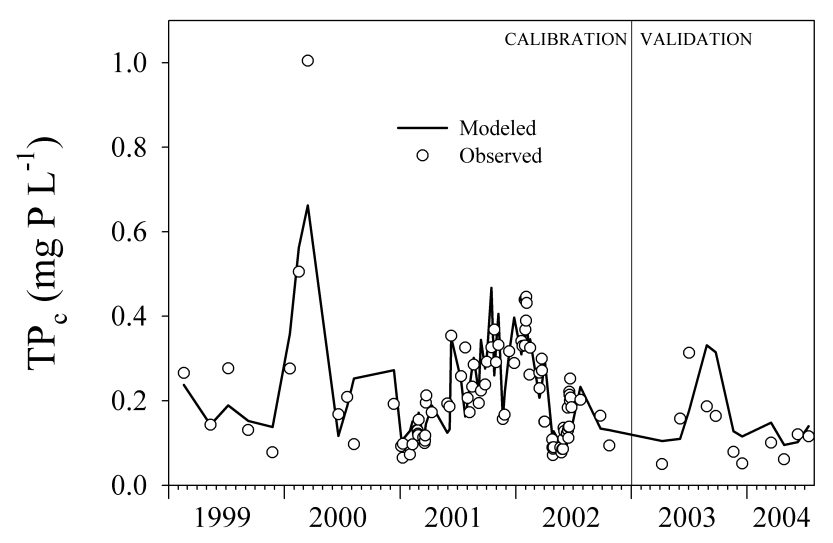

Fig. 4. Time trace of observed corrected total phosphorus concentration $\left(\mathrm{TP}_{c}\right)$ values and model outcomes at Roda de Ter during calibration and validation periods.

with the time series of $Q_{i}$ and $Q_{g}$ we obtained mean annual TP loads of $23600 \mathrm{~kg} \mathrm{Pyr}^{-1}$ from groundwater discharge and $12800 \mathrm{~kg} \mathrm{P} \mathrm{yr}^{-1}$ from interflow discharge.

The mass transfer coefficient $v_{f}$ was optimized to a very low value (Table 1), and the temperature correction factor (TC, Table 1) was adjusted to 1.06. Considering that mean daily river water temperature in the watershed ranges from 5 to $27^{\circ} \mathrm{C}$ (Fig. 3), this means that $v_{f}$ values were multiplied by a factor (Eq. 4) that ranged from 0.4 to 1.3. Thus, actual $v_{f}$ values after temperature correction ranged between $5.6 \times 10^{-7}$ and $1.8 \times 10^{-6} \mathrm{~m} \mathrm{~s}^{-1}$. Mean $v_{f}$ for two nutrient retention experiments in a reach in the impaired Riera de Tona (Gurri River tributary, Fig. 1b) was $4.6 \times 10^{-6} \mathrm{~m} \mathrm{~s}^{-1}$ (Martí et al., 2004), which is an astonishingly similar figure compared to our adjusted value (Table 1).

The fit between observed data and model outcomes at Roda de Ter was satisfactory (Fig. 4). The model explained $72 \%$ of variance in river $\mathrm{TP}_{c}$ values during the calibration period. The contribution of the very high value during year 2000 was modest. Without this point the explained variance amounted 69\%. It is interesting to note that using Martí et al.'s empirical $v_{f}$ value only caused a slight deviation in the model results ( $66 \%$ of TP explained variance compared to $72 \%$ with the optimized parameter). However, the model performed worse during high flow conditions (or low TP concentrations), as Fig. 5 clearly shows. This was most evident during the validation period, a very wet period (Fig. 3). In addition, the fit between median TP values coming from ACA stations and model results was good (Fig. 6), although ACA station 7 showed observed values that were considerably higher than model outcomes.

From results found in the literature (Table 2), a clear power relationship could be established between $S_{w}$ values and discharge (Fig. 7a). This relationship could be split differentiating pristine streams $\left(1764 Q^{0.67}, n=46, p<0.0001\right.$, $\left.r^{2}=0.55\right)$ and data coming from nutrient-enriched streams 


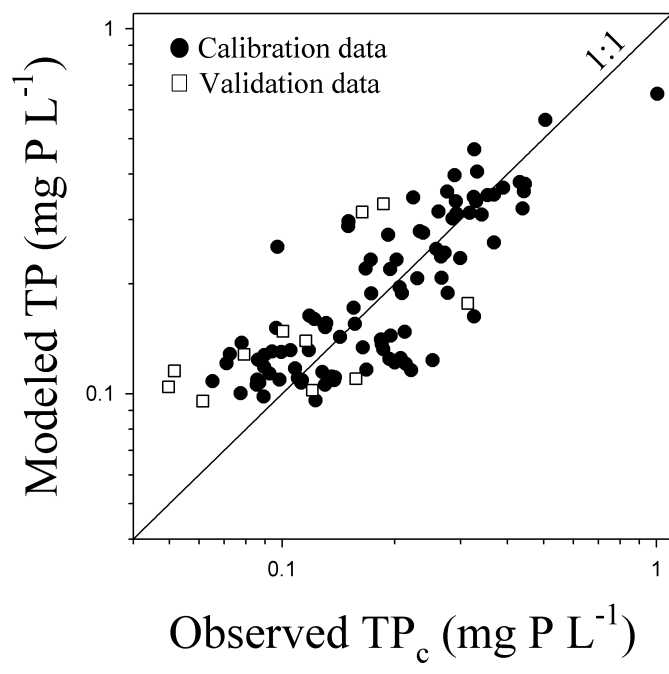

Fig. 5. Observed corrected total phosphorus concentration $\left(\mathrm{TP}_{C}\right)$ values versus modeled total phosphorus (TP) at Roda de Ter during calibration and validation periods.

(13 $\left.163 Q^{0.51}, n=20, p<0.0097, r^{2}=0.32\right)$. We reevaluated the power regression for impaired streams discarding points labeled as j, r, and n (21 $256 Q^{0.49}, n=17, p<0.0001$, $r^{2}=0.73$, bold line in Fig. 7a). The presence of these points, which represent very short phosphorus $S_{w}$ in nutrient enriched streams, should be attributed to methodological constraints. Most of the nutrient retention experiments in impaired streams were measuring net retention. Since in impaired streams point sources and diffuse inputs can be inextricably linked (Merseburger et al., 2005), it is not easy to assign this low $S_{w}$ to the effect of actual in-stream processes or to lateral inflows of nutrients by seepage. Mean $S_{w}$ for the Ter River calculated with our model is also indicated in the plot (Fig. 7a, full triangle), and falls near the result expected for an impaired system.

$S_{w}$ also showed a significant relationship with phosphorus concentration (PC) in streams (Fig. 7b), although both level of significance and explained variance were low, specially for nutrient enriched streams (185350 $P C^{-0.46}, n=17$, $p=0.016, r^{2}=0.33$ for impaired streams without outliers, and $43 P C^{0.65}, n=46, p=0.007, r^{2}=0.17$ for pristine systems). Remarkably, slope of the power regression differed between stream type (Fig. 7b), and the power regression using all data was significant $\left(55.2 P C^{0.6}, n=57, p<0.0001\right.$, $r^{2}=0.56$ ).

Contrastingly, $v_{f}$ and streamflow did not show any significant relationship when pristine and impaired streams were analyzed separately (Fig. 7c), although a significant negative power law exist pooling both types of systems $\left(9.8 \times 10^{-6} P C^{-0.3}, n=57, p=0.0017, r^{2}=0.16\right)$. On the other hand, only $v_{f}$ measured in pristine streams was significantly related to phosphorus concentration in streams (0.0001 $P C^{-0.46}, n=46, p=0.008, r^{2}=0.18$, Fig. 7D), al-

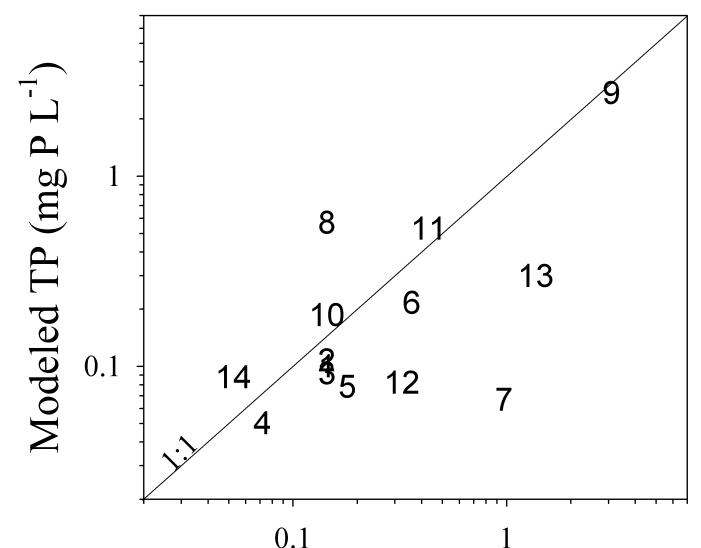

Observed TP (mg P L $\left.{ }^{-1}\right)$

Fig. 6. Median total phosphorus (TP) values observed in the different sampling stations sampled by the Catalan Water Agency (ACA) against modeled values (numbers as in Fig. 1a).

though again we found a significant negative power law when pooling pristine and impaired systems in the same analysis $\left(9 \times 10^{-5} P C^{-0.35}, n=57, p<0.0001, r^{2}=0.52\right)$.

\section{Discussion}

The low mass transfer coefficient $v_{f}$ optimized in our model is only comparable with values obtained in point-source impaired streams (Doyle et al., 2003; Martí et al., 2004). Values from pristine streams usually fall between $10^{-3}$ and $10^{-5} \mathrm{~m} \mathrm{~s}^{-1}$ (Doyle et al., 2003). Our low $v_{f}$ defines a watershed with watercourses with very low phosphorus retention capacity. Of course, this would probably hold in reaches around the sampling point at Roda de Ter, while in headwater streams the value will probably be underestimated. However, there is evidence that some small streams in the area have very small phosphorus retention capacity as well (Martí et al., 2004) due to the widespread human impact in the basin. Thus, with data at hand is very difficult to propose how nutrient retention varies across the stream network. In consequence, we must take our $v_{f}$ figure as a coarse-scale value. Nonetheless, considering that most relevant TP point sources are located near the sampling point at Roda de Ter, the probably biased $v_{f}$ in some headwater reaches is expected to have little impact on modeled nutrient concentrations. Another evident limitation of our procedure was that the spatial patterns in land use and its effect on TP loads are disregarded, since groundwater and interflow TP concentrations are simply functions of flow. We acknowledge that this is an important point, and that this could promote some bias in the results. However, we must take into account that although we had very detailed data on land uses distribution, nutrient concentration data came from only one station. Consequently, 
Table 2. Uptake length $\left(S_{w}\right)$, mass transfer velocity $\left(v_{f}\right)$, discharge, and ambient phosphorus concentration for different nutrient retention experiments in pristine and impaired streams. Figures labeled with an asterisk represent net retention values. $n a=$ not available.

\begin{tabular}{|c|c|c|c|c|c|c|}
\hline & System & $\begin{array}{l}\text { Discharge } \\
\left(\mathrm{m}^{3} \mathrm{~s}^{-1}\right)\end{array}$ & $\begin{array}{l}S_{w} \\
(\mathrm{~m})\end{array}$ & $\begin{array}{r}v_{f} \\
\left(\mathrm{~ms}^{-1}\right)\end{array}$ & $\begin{array}{l}\text { Concentration } \\
\left(\mathrm{mg} \mathrm{P} \mathrm{m}^{-3}\right)\end{array}$ & Source \\
\hline \multicolumn{7}{|c|}{ Pristine streams } \\
\hline 1 & Riera Major (Spain) & 0.0544 & 300 & $2.48 \times 10^{-5}$ & 11.7 & Butturini and Sabater (1998) \\
\hline 2 & Pine Stream (USA) & 0.0021 & 49 & na & na & D'Angelo and Webster (1991) \\
\hline 3 & Hardwood Stream (USA) & 0.0025 & 31 & na & na & D'Angelo and Webster (1991) \\
\hline 4 & Pioneer Creek (USA) & 0.0856 & 370 & $1.21 \times 10^{-4}$ & 5.0 & Davis and Minshall (1999) \\
\hline 5 & Bear Brook (USA) & 0.0145 & 49 & $1.12 \times 10^{-4}$ & 1.5 & Hall et al. (2002) \\
\hline 6 & Cone Pond outlet (USA) & 0.0023 & 8 & $1.87 \times 10^{-4}$ & 1.5 & Hall et al. (2002) \\
\hline 7 & Hubbard Brook (USA) & 0.0866 & 85 & $9.98 \times 10^{-5}$ & 1.5 & Hall et al. (2002) \\
\hline 8 & Paradise Brook (USA) & 0.0067 & 29 & $1.03 \times 10^{-4}$ & 1.5 & Hall et al. (2002) \\
\hline 9 & W2 stream (USA) & 0.0011 & 6 & $1.15 \times 10^{-4}$ & 1.5 & Hall et al. (2002) \\
\hline 10 & W3 stream (USA) & 0.0069 & 22 & $1.36 \times 10^{-4}$ & 1.5 & Hall et al. (2002) \\
\hline 11 & W4 stream (USA) & 0.0042 & 14 & $1.37 \times 10^{-4}$ & 1.5 & Hall et al. (2002) \\
\hline 12 & W5 stream (USA) & 0.0016 & 19 & $5.23 \times 10^{-5}$ & 1.5 & Hall et al. (2002) \\
\hline 13 & W6 stream (USA) & 0.0027 & 15 & $1.10 \times 10^{-4}$ & 1.5 & Hall et al. (2002) \\
\hline 14 & West Inlet to Mirror Lake (USA) & 0.0010 & 12 & $6.17 \times 10^{-5}$ & 1.5 & Hall et al. (2002) \\
\hline 15 & Myrtle Creek (Australia) & 0.0049 & 76 & $5.60 \times 10^{-5}$ & 29.0 & Hart et al. (1992) \\
\hline 16 & Montesina Stream (Spain) & 0.0019 & 8 & $3.05 \times 10^{-4}$ & 8.7 & Maltchik et al. (1994) \\
\hline 17 & Riera Major (Spain) & 0.0578 & 177 & $1.71 \times 10^{-4}$ & 19.9 & Martí and Sabater (1996) \\
\hline 18 & La Solana Stream (Spain) & 0.0207 & 89 & $9.47 \times 10^{-5}$ & 7.9 & Martí and Sabater (1996) \\
\hline 19 & West Fork (USA) & 0.0042 & 65 & $3.96 \times 10^{-5}$ & 3.5 & Mulholland et al. (1985) \\
\hline 20 & Walter Branch (USA) & 0.0060 & 167 & na & 3.0 & Munn and Meyer (1990) \\
\hline 21 & Watershed 2, Oregon (USA) & 0.0010 & 697 & $5.20 \times 10^{-6}$ & 5.0 & Munn and Meyer (1990) \\
\hline 22 & Hugh White Creek (USA) & 0.0040 & 85 & $3.10 \times 10^{-4}$ & 1.0 & Munn and Meyer (1990) \\
\hline 23 & Coweeta Stream (USA) & 0.0022 & 9 & na & na & Newbold (1987) \\
\hline 24 & Sturgeon River (USA) & 1.2600 & 1400 & na & na & Newbold (1987) \\
\hline 25 & West Fork, 1st order (USA) & 0.0042 & 165 & na & na & Newbold (1987) \\
\hline 26 & West Fork, 2nd order (USA) & 0.0310 & 213 & na & na & Newbold (1987) \\
\hline 27 & West Fork (USA) & 0.0046 & 190 & $1.12 \times 10^{-5}$ & 4.0 & Newbold et al. (1983) \\
\hline 28 & Barbours Stream (New Zealand) & 0.0450 & 289 & $9.30 \times 10^{-5}$ & 1.5 & Niyogi et al. (2004) \\
\hline 29 & Kye Burn Stream (New Zealand) & 0.0240 & 388 & $7.50 \times 10^{-5}$ & 1.0 & Niyogi et al. (2004) \\
\hline 30 & Stony Stream (New Zealand) & 0.0700 & 266 & $1.06 \times 10^{-4}$ & 2.0 & Niyogi et al. (2004) \\
\hline 31 & Sutton Stream (New Zealand) & 0.0530 & 872 & $2.15 \times 10^{-5}$ & 2.0 & Niyogi et al. (2004) \\
\hline 32 & Lee Stream (New Zealand) & 0.0710 & 240 & $3.50 \times 10^{-5}$ & 12.0 & Niyogi et al. (2004) \\
\hline 33 & Broad Stream (New Zealand) & 0.1550 & 920 & $5.15 \times 10^{-5}$ & 15.5 & Niyogi et al. (2004) \\
\hline 34 & Dempsters Stream (New Zealand) & 0.0290 & 669 & $1.80 \times 10^{-5}$ & 8.0 & Niyogi et al. (2004) \\
\hline 35 & Kuparuk River (Alaska) & 1.3500 & 2955 & $3.28 \times 10^{-5}$ & 14.5 & Peterson et al. (1993) \\
\hline 36 & East Kye Burn (New Zealand) & 0.0150 & 94 & $1.17 \times 10^{-4}$ & 2.0 & Simon et al. (2005) \\
\hline 37 & North Kye Burn (New Zealand) & 0.0230 & 222 & $6.67 \times 10^{-5}$ & 2.0 & Simon et al. (2005) \\
\hline 38 & JK1-JK3 streams (USA) & 0.0082 & 42 & $1.80 \times 10^{-4}$ & 4.3 & Valett et al. (2002) \\
\hline 39 & SR1-SR3 streams (USA) & 0.0052 & 87 & $4.00 \times 10^{-5}$ & 5.0 & Valett et al. (2002) \\
\hline 40 & Cunningham Creek (USA) & 0.0097 & 104 & $1.67 \times 10^{-4}$ & 1.0 & Wallace et al. (1995) \\
\hline 41 & Cunningham Creek after logging (USA) & 0.0252 & 47 & $6.87 \times 10^{-4}$ & 1.0 & Wallace et al. (1995) \\
\hline 42 & Hugh White Creek (USA) & 0.0190 & 30 & $2.45 \times 10^{-5}$ & 2.0 & Webster et al. (1991) \\
\hline 43 & Sawmill Branch (USA) & 0.0025 & 32 & $2.40 \times 10^{-5}$ & 7.0 & Webster et al. (1991) \\
\hline 44 & Big Hurricane Branch (USA) & 0.0177 & 31 & $1.59 \times 10^{-5}$ & 5.0 & Webster et al. (1991) \\
\hline 45 & Perennial stream (Spain) & 0.0159 & 406 & $1.17 \times 10^{-5}$ & 13.0 & von Shiller et al. (2008) \\
\hline 46 & Intermittent stream (Spain) & 0.0200 & 385 & $1.00 \times 10^{-5}$ & 5.0 & von Shiller et al. (2008) \\
\hline
\end{tabular}


Table 2. Continued.

\begin{tabular}{|c|c|c|c|c|c|c|}
\hline & System & $\begin{array}{r}\text { Discharge } \\
\left(\mathrm{m}^{3} \mathrm{~s}^{-1}\right)\end{array}$ & $\begin{array}{l}S_{w} \\
(\mathrm{~m})\end{array}$ & $\begin{array}{r}v_{f} \\
\left(\mathrm{~ms}^{-1}\right)\end{array}$ & $\begin{array}{r}\text { Concentration } \\
\left(\mathrm{mg} \mathrm{P} \mathrm{m}^{-3}\right)\end{array}$ & Source \\
\hline \multicolumn{7}{|c|}{ Nutrient-enriched streams } \\
\hline $\mathrm{a}$ & Koshkonong River without dam (USA) & 6.2107 & $57449 *$ & $4.47 \times 10^{-6}$ & 157.4 & Doyle et al. (2003) \\
\hline $\mathrm{b}$ & Koshkonong River with dam (USA) & 12.7500 & $188115^{*}$ & $2.56 \times 10^{-6}$ & 153.0 & Doyle et al. (2003) \\
\hline $\mathrm{c}$ & Demmitzer Mill Brook (Germany) & 0.0220 & 4144 & $5.37 \times 10^{-6}$ & 112.1 & Gücker and Pusch (2006) \\
\hline $\mathrm{d}$ & Erpe Brook (Germany) & 0.5110 & 5539 & $2.46 \times 10^{-6}$ & 203.8 & Gücker and Pusch (2006) \\
\hline $\mathrm{e}$ & Columbia Hollow (USA) & 0.1183 & $8667 *$ & $4.55 \times 10^{-6}$ & 5940.0 & Haggard et al. (2005) \\
\hline$f$ & Fosso Bagnatore (Italy) & 0.0099 & 3480 & $2.22 \times 10^{-6}$ & 676.7 & Ruggiero et al. (2006) \\
\hline g & Daró Stream (Spain) & 0.0460 & $3510 *$ & $4.23 \times 10^{-6}$ & 426.2 & Martí et al. (2004) \\
\hline $\mathrm{h}$ & Riera de Tenes (Spain) & 0.0045 & $2080^{*}$ & $2.13 \times 10^{-5}$ & 6972.0 & Martí et al. (2004) \\
\hline $\mathrm{i}$ & Riera de Berga (Spain) & 0.0710 & $14250^{*}$ & $4.15 \times 10^{-6}$ & 3084.1 & Martí et al. (2004) \\
\hline $\mathrm{j}$ & Riera d'en Pujades (Spain) & 0.0180 & $170 *$ & $1.18 \times 10^{-4}$ & 6713.6 & Martí et al. (2004) \\
\hline $\mathrm{k}$ & Riera de Tona (Spain) & 0.0305 & $7550 *$ & $4.50 \times 10^{-6}$ & 4494.0 & Martí et al. (2004) \\
\hline 1 & Ondara Stream (Spain) & 0.0600 & $2560 *$ & $1.95 \times 10^{-5}$ & 3226.0 & Martí et al. (2004) \\
\hline $\mathrm{m}$ & Verneda Stream (Spain) & 0.0250 & $3200 *$ & $7.10 \times 10^{-6}$ & 6750.0 & Martí et al. (2004) \\
\hline $\mathrm{n}$ & Riera de Figueres (Spain) & 0.1630 & $250^{*}$ & $3.43 \times 10^{-4}$ & 2683.7 & Martí et al. (2004) \\
\hline o & Passerell Stream (Spain) & 0.0120 & $4790 *$ & $1.39 \times 10^{-6}$ & 5442.5 & Martí et al. (2004) \\
\hline $\mathrm{p}$ & Barrenys Stream (Spain) & 0.1500 & $2490 *$ & $2.62 \times 10^{-5}$ & 7143.7 & Martí et al. (2004) \\
\hline $\mathrm{q}$ & Negre Stream (Spain) & 0.0220 & $2120 *$ & $1.04 \times 10^{-5}$ & 5241.0 & Martí et al. (2004) \\
\hline $\mathrm{r}$ & Salat Stream (Spain) & 0.0530 & $50 *$ & $1.32 \times 10^{-3}$ & 788.4 & Martí et al. (2004) \\
\hline s & Riera d'Osor (Spain) & 0.0310 & $2850^{*}$ & $6.40 \times 10^{-6}$ & 2392.9 & Martí et al. (2004) \\
\hline $\mathrm{t}$ & Llobregat de la Muga (Spain) & 0.0470 & $3740 *$ & $5.03 \times 10^{-6}$ & 1572.9 & Martí et al. (2004) \\
\hline
\end{tabular}

any attempt to include spatial variability in TP model components would have been a worthless effort.

The significant dependence on water temperature suggested that $v_{f}$ for TP in this watershed is controlled to some extent by biological activity. However, as an empirical correction factor, this could also reflect any seasonal process related to TP retention showing covariance with stream temperature. Thus, results from this study cannot be used to state that temperature is modulating TP retention.

Concerning the model fit, it seemed that the model was missing some significant effect at high flows, which could be attributed to physically-mediated higher retention during high flows not accounted for in our formulation, or to an overestimation of $\mathrm{TP}_{g}$ during very wet periods. Considering that during high flows river nutrient concentration is quite small because dilution, it is not probable that a formulation including saturation kinetics for retention would help solving this misfit. One possible reason for the misfit could be the presence of an additional inorganic retention process taking place in the water column and specially significant during high flows. This points to a model with two loss mechanisms: the areal retention already included related to biological activity, and one additional volumetric loss rate related to particulate TP retention (the presence of a significant biological loss process taking place in the water column is not feasible considering the size of the Ter River). This is a suggestive hypothesis to test in future versions of the model.
Concerning the data from ACA stations, low TP values modeled for ACA station 7 should be attributed to a missing point source in the database upstream from this sampling point, considering that the adjusted $v_{f}$ value for the watershed represented a very low retention efficiency.

Despite these shortcomings, results from this study showed that the formulation on which the Nutrient Spiralling concept research is based is a good alternative for modeling the nutrient in-stream processes in a watershed-scale model. Even considering that we worked in a worst case scenario, in the sense that limited river TP concentration data were available to calibrate the model, model outcomes were satisfactory. Taking into account the similarity between our adjusted $v_{f}$ and values reported by Martí et al. (2004) for streams in the Ter River watershed, adjusted parameter values can be considered realistic.

A more general test of the adequacy of the model structure is the comparison with retention metrics coming from impaired streams of the world and their relationships with streamflow and nutrient concentration. The dependence of $S_{w}$ on streamflow was already reported for phosphorus (Butturini and Sabater, 1998) and ammonia retention (Peterson et al., 2001) in pristine streams. Our fitted power relationship between $S_{w}$ and discharge in pristine streams slightly differed from the equation reported by Butturini and Sabater (1998), because our database includes recent data. However, the most interesting fact in Fig. 7a was that a significant 


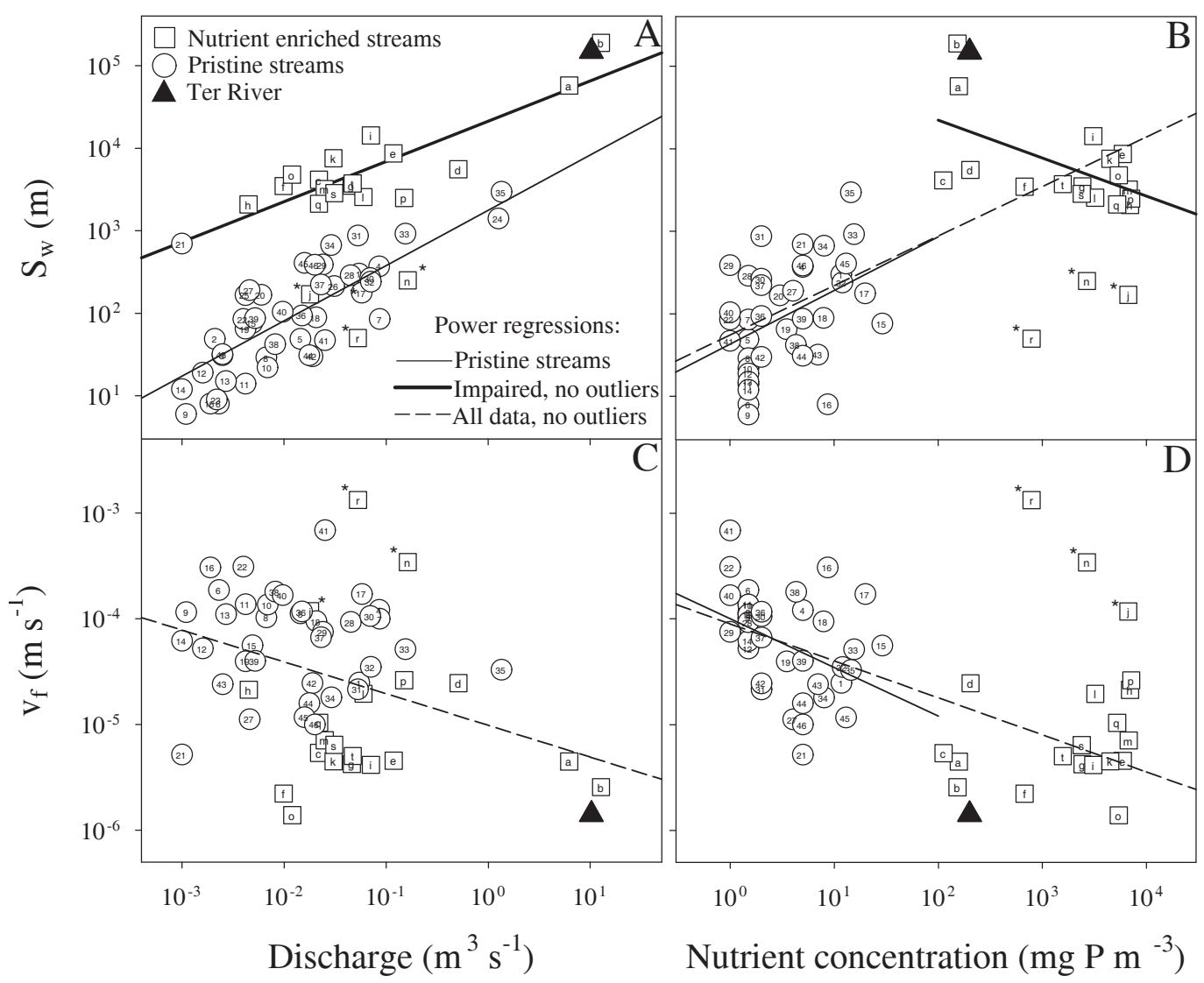

Fig. 7. Discharge and phosphorus ambient concentration versus phosphorus $S_{w}$ and $v_{f}$ for pristine and nutrient enriched streams. Numbers and letters are as in Table 2. Points labeled with an asterisk are considered outliers. Results for our model are depicted as full triangles. See the text for details on power regressions.

power relationship was also fitted with data coming from nutrient-enriched streams. The agreement between the mean $S_{w}$ value obtained with our model for the Ter River and the expected result for an impaired stream with similar discharge (full triangle in Fig. 7a) is notable, and suggest that the model structure used in our model is adequate and realistic.

Our results suggest that the lack of relationship between phosphorus $S_{w}$ and discharge reported in impaired streams (Martí et al., 2004) can be attributed to a narrower discharge range in previous studies. In fact, the relationship between $S_{w}$ and discharge can be considered a worthless result considering Eq. (5) (Stream Solute Workshop, 1990), where the dependence of $S_{w}$ on hydrology is clearly stated. See the open discussion in Marcé and Armengol (2009) for a debate on this subject. In the case of phosphorus, it cannot be argued that the variability in the biological loss process $\left(v_{f}\right.$ in Eq. (5)) is responsible for a great portion of the $S_{w}$ vs. discharge relationship, because neither pristine nor impaired streams showed $v_{f}$ dependence on streamflow (Fig. 7c). This conclusion is also supported by the fact that the slopes of power laws drawn in Fig. 7a hardly deviate from 0.6, which is the most probable slope if $S_{w}$ variability were mainly determined by hydraulics as defined in Eq. $(5)\left(u \approx Q^{0.2}\right.$ and $h \approx Q^{0.4}$, Knighton (1998)). However, the different intercept of the power regressions showed by pristine and impaired streams is a robust result. The difference in mean $v_{f}$ between stream classes is about two orders of magnitude $\left(1 \times 10^{-4} \mathrm{~m} \mathrm{~s}^{-1}\right.$ for pristine streams and $8.6 \times 10^{-6} \mathrm{~m} \mathrm{~s}^{-1}$ for impaired ones), as is the case for the difference between mean $S_{w}$ values $(270 \mathrm{~m}$ for pristine streams and $25828 \mathrm{~m}$ for impaired streams). Considering Eq. (5) and these results, most probably the different intercepts in the $S_{w}$ vs. discharge relationship are a rate constant effect more than an effect of the dependence of the intercepts on velocity (since $S_{w}$ can be defined as $u / k_{c}$ and discharge as $u A$ ). This result agree with the analysis in Doyle et al. (2003), who emphasized the coupled nature of channel morphology and uptake processes for governing phosphorus retention, and coincides with Alenxander et al. (2009) who reached the same conclusion for nitrogen.

$v_{f}$ shows significant dependence on discharge when data for pristine and impaired streams are lumped in the analysis 
(Fig. 7c). However, we consider that this result could have arose by chance, since $v_{f}$ values are split in two groups depending on stream class, and high stream values are only present for impaired streams. The fact that intra-class relationships were not significant supports this view. Thus, care should be taken when using discharge to scale in-stream phosphorus retention processes to the watershed scale, a current practice for nitrogen (Alexander et al., 2000). In our opinion, the same artifact could be present in the relationships between nutrient retention metrics and phosphorus ambient concentration (Fig. $7 \mathrm{~b}$ and $7 \mathrm{~d}$ ). Relationships for pristine streams, despite explaining a little portion of retention metrics variability, can be considered reliable, and in fact have been recently described for phosphorus in pristine streams (von Shiller et al., 2008). However, significant relationships lumping data for all streams could be an artifact, since it seems that regressions are fitting two clouds of data points. This would be the case if retention metrics in impaired streams were independent of nutrient concentration, but dependent on other impacts (e.g., biological community composition, geomorphological modifications, toxic pollutants). An alternative explanation is that impaired and pristine streams share the same kinetics, but from $10^{2} \mathrm{mg} \mathrm{P} \mathrm{m}^{-3}$ retention processes loss sensitivity to nutrient concentration, as proposed for nitrogen in streams with cronic high nutrient loads (Bernot and Doods, 2005). However, $v_{f}$ for nitrogen in streams shows a significant power relationship throughout five orders of magnitude in nitrate concentration values (Mulholland et al., 2008; Alenxander et al., 2009), and the relationship is consistent for rivers associated to different human impacts. The uncertainty of our results compared to the well defined patterns described for nitrogen could be the result of the very heterogeneous methodologies involved in the figures collected in Table 1, but the importance of inorganic processes in stream phosphorus chemistry could also play a role. With no doubt, more research on phosphorus retention should be done to definitively answer if phosphorus retention follows a dynamics similar to that of nitrogen, or if a idiosyncratic framework should be developed for phosphorus.

In any case, panels in Fig. 7 clearly state that nutrient enriched streams shows retention efficiency loss. This is not at odds with Mulholland et al. (2008) results for nitrogen, that shows not so evident differences between stream types. The reason is that we used nutrient concentration as the criteria for defining a stream as impaired, while Mulholland et al. (2008) separated streams by land use adjacent to the stream. Thus, urban and agricultural streams in Mulholland et al. (2008) actually included streams with very low nutrient concentration. Considering the tight relationship between nitrogen $v_{f}$ and stream concentration reported by Mulholland et al. (2008), applying our criteria for defining an impaired stream should result in retention efficiency loss in impaired streams also for nitrogen.

Interestingly, phosphorus retention efficiency loss in impaired streams is maintained in the whole discharge range
(Fig. 7a). Thus, human impacts on nutrient retention are significant across the entire stream network, and not restricted to small water courses. This has enormous implications, because it has been frequently argued that small streams are hot spots for nutrient retention in stream networks (Peterson et al., 2001). Without posing in question this assertion, Wollheim et al. (2006) showed that the relevance of big and small streams depends on the level of aggregation for which removal is reported. In any case, Wollheim et al. (2006) demonstrated that larger rivers can exert considerable influence on nutrient exports, and that altering these systems could have a disproportionate impact on basin exports. Results collected here suggest that human pressure alter phosphorus processing even in large rivers, and considering Wollheim et al. (2006) results this should promote further research on phosphorus retention metrics in larger rivers (e.g., Tank et al., 2008).

\section{Conclusions}

We have demonstrated that a lumped, hardly parameterized formulation of the in-stream nutrient fate in rivers could be very efficient in a large-scale model, and that this opens the very interesting possibility of directly using data collected in the field in large-scale applications. Although other authors already proposed watershed scale models including formulations coming from the Nutrient Spiralling concept to solve the in-stream processes (e.g., Wollheim et al., 2006; Alenxander et al., 2009), here we showed that this approach may be helpful even for customary deterministic applications working at short time steps (e.g. SWAT or HSPF applications at hourly intervals). Our procedure avoids the exercise of upscaling fine-scale research results to parameterize doeverything in-stream modules typical of such models, which are finally adjusted to bibliographical values on most occasions. Of course, this is not a valid option if the detailed biogeochemical processes are research targets, or if we need explicit formulations of these processes to simulate complex biotic or abiotic interactions. However, the coarse-formulation approach should suffice in many modeling exercises that are usually solved using highly parameterized model structures.

On the other hand, analysis of published data on phosphorus retention in streams strongly suggested that impaired streams have less phosphorus retention efficiency caused by a diminution of in-stream uptake processes. Remarkably, phosphorus retention efficiency loss in impaired streams is maintained in the whole discharge range. Considering the scarce information available on phosphorus retention in large streams and rivers, this should be considered a research priority if we want to upscale phosphorus retention to entire stream networks located in populated areas. Unfortunately, the association between phosphorus retention efficiency (expressed as $v_{f}$ ) and discharge and phosphorus concentration in streams are much more uncertain than reported for 
nitrogen, specially if impaired streams are present. Thus, further research is needed to clarify the biogeochemical controls of phosphorus retention in streams at the reach scale, specially in large watercourses. The possibility of including an independent inorganic kinetic component in the nutrient spiralling formulation for phosphorus should also be investigated.

Acknowledgements. We thank M. Comerma, J. C. García, M. A. Gallegos, J. Ordóñez, and G. González for the field work. ATLL and ACA gently provided data. Founding was provided by the Spanish Plan Nacional de I+D+I (Projects CGL2004-05503CO2-01 and CGL2008-06377-C02-01). Comments from referees and editor during open discussion greatly enhanced the quality of this paper.

Edited by: M. Sivapalan

\section{References}

Alexander, R. B., Smith, R. A., and Schwarz, G. E.: Effect of stream channel size on the delivery of nitrogen to the Gulf of Mexico, Nature, 403, 758-761, 2000.

Alexander, R. B., Johnes, P. J., Boyer, E., and Smith, R. A.: A comparison of models for estimating the riverine export of nitrogen from large watersheds, Biogeochemistry, 57/58, 295-339, 2002.

Alexander, R. B., Böhlke, J. K., Boyer, E. W., David, M. B., Harvey, J. W., Mulholland, P. J., Seitzinger, S. P., Tobias, C. R., Tonitto, C., and Wollheim, W. M.: Dynamic modeling of nitrogen losses in river networks unravels the coupled effects of hydrological and biogeochemical processes, Biogeochemistry, 93, 91-116, 2009.

Beaulac, M. N. and Reckhow, K. H.: An examination of land use-nutrient export relationships, Water Resour. Bull., 18, 10131024, 1982.

Behrendt, H., Huber, P., Kornmilch, M., Opitz, D., Schmoll, O., Scholz, G., and Uebe, R.: Nutrient emissions into river basins of Germany, UBATexte 23/00, Berlin, 2000.

Bernot, M. J. and Doods, W. K.: Nitrogen retention, removal, and saturation in lotic ecosystems, Ecosystems, 8, 442-453, 2005.

Beven, K.: Changing ideas in hydrology: the case of physicallybased models, J. Hydrol., 105, 157-172, 1989.

Bicknell, B. R., Imhoff, J. C., Kittle, J. L., Jobes, T. H., and Donigian, A. S.: Hydrological Simulation Program-Fortran (HSPF) user's manual for release 12. US Environmental Protection Agency, National Exposure Research Laboratory, Athens, GA, 2001.

Butturini, A. and Sabater, F.: Ammonium and phosphate retention in a Mediterranean stream: hydrological versus temperature control, Can. J. Fish. Aquat. Sci., 55, 1938-1945, 1998.

Consell Comarcal d'Osona: Actions, present condition, and future scenarios for the Manure Management Plan in Osona, Consell Comarcal d'Osona, Vic, Spain, 2003 (in Catalan).

D'Angelo, D. J. and Webster, J. R.: Phosphate retention in streams draining pine and hardwood catchments in the southern Appalachian mountains, Freshwater Biol., 26, 335-345, 1991.

Davis, J. C. and Minshall, G. W.: Nitrogen and phosphorus uptake in two Idaho (USA) headwater wilderness streams, Oecologia, 119, 247-255, 1999.
Doherty, J.: PEST Surface Water Utilities, Watermark Numerical Computing and University of Idaho, Brisbane, Australia, 2003.

Doyle, M. W., Stanley, E. H., and Harbor, J. M.: Hydrogeomorphic controls on phosphorus retention in streams, Water Resour. Res. 39, 1147, doi:10.1029/2003WR002038, 2003.

Duan, Q., Sorooshian, S., and Gupta, V.: Effective and efficient global optimization for conceptual rainfall-runoff models, Water Resour. Res., 28, 1015-1031, 1992.

Garnier, J., Billen, G., and Coste, M.: Seasonnal succession of diatoms and Chlorophyceae in the drainage network of the river Seine: Observations and modeling, Limnol. Oceanogr., 40, 750 765, 1995.

Grasshoff, K., Erhardt, M., and Kremling, K.: Methods of Sea Water Analyses, Verlag Chemie, Weinheim, Germany, 1983.

Gücker, B. and Pusch, M. T.: Regulation of nutrient uptake in eutrophic lowland streams, Limnol. Oceanogr., 51, 1443-1453, 2006.

Haggard, B. E., Stanley, E. H., and Storm, D. E.: Nutrient retention in a point-source-enriched stream, J. N. Am. Benthol. Soc., 24 29-47, 2005.

Hall, R. J., Bernhardt, E. S., and Likens, G. E.: Relating nutrient uptake with transient storage in forested mountain streams, Limnol. Oceanogr., 47, 255-265, 2002.

Hart, B. F., Freeman, P., and McKelvie, I. D.: Whole-stream phosphorus release studies-Variation in uptake length with initial phosphorus concentrations, Hydrobiologia, 235, 573-584, 1992.

Heaney, S. I., Corry, J. E., and Lishman, J. P.: Changes of water quality and sediment phosphorus of a small productive lake following decreased phosphorus loading, in: Eutrophication: Research and Application to Water Supply, edited by: Sutcliffe, D. W. and Jones, J. G., Freshwater Biological Association, Ambleside, UK, 119-131, 1992.

Howarth, R. W., Billen, G., Swaney, D., Townsend, A., Jaworski, N., Lajtha, K., Downing, J. A., Elmgren, R., Caraco, N., Jordan, T., Berendse, F., Freney, J., Kudeyarov, V., Murdoch, P., and Zhu, Z.: Regional nitrogen budgets and riverine $\mathrm{N}$ and $\mathrm{P}$ fluxes for the drainages to the North Atlantic Ocean: natural and human influences, Biogeochemistry, 35, 75-139, 1996.

Jaworski, N. A., Groffman, P. M., Keller, A. A., and Prager, J. C.: A watershed nitrogen and phosphorus balance: the Upper Potomac River basin, Estuaries, 15, 83-95, 1992.

Johnes, P. J.: Evaluation and management of the impact of land use change on the nitrogen and phosphorus load delivered to surface waters: the export coefficient modeling approach, J. Hydrol., 183, 323-349, 1996.

Johnes, P. J., Moss, B., and Phillips, G. L.: The determination of water quality by land use, livestock numbers and population datatesting of a model for use in conservation and water quality management, Freshwater Biol., 36, 951-473, 1996.

Johnes, P. J. and Heathwaite, A. L.: Modelling the impact of land use change on water quality in agricultural catchments, Hydrol. Process., 11, 269-286, 1997.

Knighton, D.: Fluvial forms and processes: a new perspective, Oxford Univ. Press, New York, 1998.

Maltchik, L., Molla, S., Casado, C., and Montes, C.: Measurement of nutrient spiralling in a Mediterranean stream: comparison of two extreme hydrological periods, Arch. Hydrobiol., 130, 215227, 1994. 
Marcé, R., Comerma, M., García, J. C., and Armengol, J.: A neurofuzzy modelling tool to estimate fluvial nutrient loads in watersheds under time-varying human impact, Limnol. Oceanogr.Meth., 2, 342-355, 2004.

Marcé, R., Ruiz, C. E., and Armengol, J.: Using spatially distributed parameters and multi-response objective functions to solve parameterization of complex applications of semidistributed hydrological models, Water Resour. Res., 44, W02436, doi:10.1029/2006WR005785, 2008.

Marcé, R. and Armengol, J.: Modeling river water temperature using deterministic, empirical, and hybrid formulations in a Mediterranean stream, Hydrol. Process., 22, 3418-3430, doi:10.1002/hyp.6955, 2008.

Marcé, R. and Armengol, J.: Modeling nutrient in-stream processes at the watershed scale using Nutrient Spiralling metrics, Hydrol. Earth Syst. Sci. Discuss., 6, 501-533, 2009, http://www.hydrol-earth-syst-sci-discuss.net/6/501/2009/.

Martí, E., Grimm, N. B., and Fisher, S. G.: Pre- and post-flood retention efficiency of nitrogen in a Sonoran Desert stream, J. N. Am. Benthol. Soc., 16, 805-819, 1997.

Martí, E. and Sabater, F.: High variability in temporal and spatial nutrient retention in Mediterranean streams, Ecology, 77, 854869,1996

Martí, E., Aumatell, J., Godé, L., Poch, M., and Sabater, F.: Nutrient retention efficiency in streams receiving inputs from wastewater treatment plants, J. Environ. Qual., 33, 285-293, 2004.

McIsaac, G. F., David, M. B., Gertner, G. Z., and Goolsby, D. A.: Nitrate flux in the Mississippi River, Nature, 414, 166-167, 2001.

Merseburger, G. C., Martí, E., and Sabater, F.: Net changes in nutrient concentrations below a point source input in two streams draining catchments with contrasting land uses, Sci. Total Environ., 347, 217-229, 2005.

Mulholland, P. J., Newbold, J. D., Elwood, J. W., Ferren, L. A., and Webster, J. R.: Phosphate spiralling in a woodland stream: seasonal variations, Ecology, 6, 1012-1023, 1985.

Mulholland, P. J., Steiman, A. D., and Elwood, J. W.: Measurements of phosphate uptake length in streams: comparison of radiotracer and stable $\mathrm{PO}_{4}$ releases, Can. J. Fish. Aquat. Sci., 47, 2351-2357, 1990.

Mulholland, P. J., Helton, A. M., Poole, G. C., et al.: Stream denitrification across biomes and its response to anthropogenic nitrate loading, Science, 452, 202-206, 2008.

Munn, N. L. and Meyer, J. L.: Habitat-specific solute retention in two small streams: an intersite comparison, Ecology, 71, 20692082, 1990 .

Newbold, J. D., Elwood, J. W., O’Neill, R. V., and Van Winkle, W.: Measuring nutrient spiralling in streams, Can. J. Fish. Aquat. Sci., 38, 860-863, 1981.

Newbold, J. D., Elwood, J. W., O'Neill, R. V., and Sheldon, A. L.: Phosphate dynamics in a woodland stream ecosystem; a study of nutrient spiraling, Ecology, 64, 1249-1265, 1983.

Newbold, J. D.: Phosphate spiralling in rivers and river-reservoir systems: implications of a model, in: Regulated Streams, edited by: Craig, F. and Kemper, J. B., Plenum Publishing Corp., New York, USA, 303-327, 1987.

Niyogi, D. L., Simon, K. S., and Townsend, C. R.: Land use and stream ecosystem functioning: nutrient uptake in streams that contrast in agricultural development, Arch. Hydrobiol., 160, 471-486, 2004.
O'Neill, R. V. and Rust, B.: Aggregation error in ecological models, Ecol. Model., 7, 91-105, 1979.

Payn, R. A., Webster, J. R., Mulholland, P. J., Valett, H. M., and Dodds, W. K.: Estimation of stream nutrient uptake from nutrient addition experiments, Limnol. Oceanogr.-Meth., 3, 174-182, 2005.

Peterson, B. J., Deegan, L., Helfrich, J., Hobbie, J. E., Hullar, M., Moller, B., Ford, T. E., Hersey, A., Hiltner, A., Kipphut, G., Lock, M. A., Fiebig, D. M., McKinley, V., Miller, M. C., Vestal, J. R., Ventullo, R., and Volk, G.: Biological responses of tundra river to fertilization, Ecology, 74, 653-672, 1993.

Peterson, B. J., Wollheim, W. M., Mulholland, P. J., Webster, J. R., Meyer, J. L., Tank, J. L., Martí, E., Bowden, W. B., Valett, H M., Hershey, A. E., McDowell, W. H., Dodds, W. K., Hamilton, S. K., Gregory, S., and Morrall, D. D.: Control of nitrogen export from watersheds by headwater streams, Science, 292, 8690, 2001

Raat, K. J., Vrugt, J. A., Bouten, W., and Tietema, A.: Towards reduced uncertainty in catchment nitrogen modelling: quantifying the effect of field observation uncertainty on model calibration, Hydrol. Earth Syst. Sci., 8, 751-763, 2004, http://www.hydrol-earth-syst-sci.net/8/751/2004/.

Rastetter, E. B., King, A. W., Cosby, B. J., Hornberger, G. M., O'Neill, R. V., and Hobbie, J. E.: Aggregating fine-scale ecological knowledge to model coarser-scale attributes of ecosystems, Ecol. Appl., 2, 55-70, 1992.

Reynolds, C. S.: Eutrophication and management of planktonic algae: what Vollenweider couldn't tell us?, in: Eutrophication: Research and Application to Water Supply, edited by: Sutcliffe, D. W. and Jones, J. G., Freshwater Biological Association, Ambleside, UK, 4-29, 1992.

Ruggiero, A., Solimini, A. G., and Carchini, G.: Effects of a waste water treatment plant on organic matter dynamics and ecosystem functioning in a Mediterranean stream, Ann. Limnol.-Int. J. Lim., 42, 97-107, 2006.

Runkel, R. L.: Toward a transport-based analysis of nutrient spiralling and uptake in streams, Limnol. Oceanogr.-Meth., 5, 5062, 2007.

Simon, K. S., Townsend, C. R., Biggs, B. J. F., and Bowden, W. B.: Temporal variation of $\mathrm{N}$ and $\mathrm{P}$ uptake in $2 \mathrm{New}$ Zealand streams, J. N. Am. Benthol. Soc., 24, 1-18, 2005.

Smith, R. A., Schwarz, G. E., and Alexander, R. B.: Regional interpretation of water-quality monitoring data, Water Resour. Res. 33, 2781-2798, 1997.

Srinivasan, R., Arnold, J. G., Muttiah, R. S., Walker, D., and Dyke, P. T.: Hydrologic unit modeling of the United States (HUMUS), in: Advances in Hydro-Science and Engineering, edited by: Yang, S., School of Engineering, University of Mississippi, MS, 451-456, 1993.

Stream Solute Workshop: concepts and methods for assessing solute dynamics in stream ecosystems, J. N. Am. Benthol. Soc., 9, 95-119, 1990.

Tank, J. L., Rosi-Marshall, E. J., Baker, M. A., and Hall Jr., R. O.: Are rievrs just big streams? A pulse method to quantify nitrogen demand in a large river, Ecology, 89, 2935-2945, 2008.

Valett, H. M., Crenshaw, C. L., and Wagner, P. F.: Stream nutrient uptake, forest succession, and biogeochemical theory, Ecology, 83, 2888-2901, 2002. 
Vollenweider, R. A.: Scientific fundamentals of the eutrophication of lakes and flowing waters, with particular reference to nitrogen and phosphorus as factors in eutrophication, Pub. No. DAS/SAI/68.27, Organization for Economic Cooperation and Development, Directorate for Scientific Affairs, Paris, France, 1968.

von Shiller, D., Martí, E., Riera, J. L., Ribot, M., Argerich, A., Fonollà, P., and Sabater, F.: Inter-annual, annual, and aeasonal variation of $\mathrm{P}$ and $\mathrm{N}$ retention in a perennial and an intermittent stream, Ecosystems, 11, 670-687, 2008.

Wallace, J. B., Webster, J. R., and Meyer, J. L.: Influence of log additions on physical and biotic characteristics of a mountain stream, Can. J. Fish. Aquat. Sci., 52, 2120-2137, 1995.

Walsh, J. J.: Importance of continental margins in the marine biogeochemical cycling of carbon and nitrogen, Nature, 350, 53-55, 1991.
Webster, J. R., D’Angelo, D. J., and Peter, G. T.: Nitrate and phosphate uptake in streams at Cweeta Hydrologic Laboratory, Verhandlungen Internationale Vereinigung für theoretische und Angewandte Limnologie, 24, 1681-1686, 1991.

Whitehead, P. G., Wilson, E. J., and Butterfield, D.: A semidistributed Integrated Nitrogen model for multiple source assessment in Catchments (INCA): Part I - model structure and process equations, Sci. Total Environ., 210/211, 547-558, 1998.

Wollheim, W. M., Vörösmarty, C. J., Peterson, B. J., Seitzinger, S. P., and Hopkinson, C. S.: Relationship between river size and nutrient removal, Geophys. Res. Lett., 33, L06410, doi:10.1029/2006GL025845, 2006.

Young, R. A., Onstad, C. A., and Bosch, D. D.: AGNPS: An agricultural nonpoint source model, in: Computer Models of Watershed Hydrology, edited by: Singh, V. P., Water Resources Publications, Highlands Ranch, Colorado, USA, 1001-1020, 1995. 